\title{
Comparative Study on Curriculum Guidebook of Kindergarten
}

\author{
Zhaohao Nian ${ }^{1}$ \\ ${ }^{1}$ Faculty of Education, University of Palacky, Czech Republic \\ Correspondence: Zhaohao Nian, Faculty of Education, University of Palacky, Zizkovo nam 5, 77900 Olomouc, \\ Czech Republic. Tel: 420-585-63-5088.
}

Received: October 11, 2020 Accepted: December 21, 2020 Online Published: January 4, 2020

doi:10.5539/jedp.v11n1p11

URL: http://doi.org/10.5539/jedp.v11n1p11

\begin{abstract}
With the global emphasis on early childhood education, more and more countries put early childhood education as a strategic position for comprehensive national development. The kindergarten curriculum guidebook is the primary resources for the daily teaching in kindergartens, ensuring the effectiveness and regulatory in kindergarten teaching. Therefore, it is crucial to learn how to analyze and evaluate the kindergarten curriculum guidebook and make education more scientific and comprehensive. From an international comparative perspective, this study selected two sets of kindergarten guidebooks between China and South Korea have carried on the comparative analysis and study from five aspects: the guiding ideology, frame structure, general goal, educational contents, and implementation characteristic (Crossley \& Watson, 2003). The results provide kindergarten educators a reference to reflect on the focus of the domestic kindergarten curriculum's educational content and the country's current educational problems and try to find possible causes or solutions from international comparisons.
\end{abstract}

Keywords: curriculum guidebook, comparative analysis, kindergarten curriculum.

\section{Introduction}

This study is an international comparative study on the kindergarten curriculum guidebook. The selected bojects are all applicable to above five-year old children of kindergarten. Both of them are certified by the national authority and widely used.

\subsection{China: "Kindergarten Experience ·Exploring · Communication Curriculum" Guidebook}

This curriculum guidebook is China's national standard vision that divides the main activities into three categories: experience, exploring, and communication (Xia \& Jin, 2012). Experience refers to a kind of identity relationship between people and the external world. It is the emotion, personality, and process acquired by people in direct communion with the world around them. In early childhood, all actions have a strong sense of experience. Exploring refers to the unity of opposites between man and the outside world, recognizing that children have the instinct of inquiry. The awareness of the problem slowly and profoundly learning. Explore and experience are closely combined, and the process of inquiry is showed by vivid images and distinct emotions and emotions. Communication refers to the relationship with people in society. Human beings are social, and from the day they are born, they are in many interpersonal relationships. Human interaction is also a complex and emotional interaction. From the kindergarten curriculum perspective, communication includes the communication and cooperation between kindergarten teachers and students, the community and parents (Qiu, 2019). The sharing, display, evaluation, and other links that pay special attention to specific activities are all forms of communication. It tries to let children feel the nature and the society around them from the perspective of "myself," thus forming three content dimensions: "myself," "me and nature," and "me and society." According to the investigation, most kindergartens in China use this version of curriculum materials, which has strong representativeness. Therefore, this version is as one of the research objects in this study.

\subsection{South Korea: Kindergarten Global Curriculum Guidebook}

Kindergarten Global Curriculum in South Korea belongs standard curriculum guidebook that is necessary for the implementation of kindergarten. The global Curriculum announcements and the understanding books accompanying the teacher's instruction manual provide valuable guidance to all kindergartens and children's homes that adopt in South Korea. This course guidebook covers kindergarten education, composition, and evaluation of indoor and outdoor environments. It is a reference book for teachers in kindergartens and children's homes to carry out education and teaching activities for children according to education and care activities (Lee, 
1996). The curriculum guidebook also sets common and general standards for achieving the educational goals and activities of the kindergarten's global curriculum.

\section{Methodology}

The main research methods used in this study are comparative analysis and literature research methods.By comparing the selected representative kindergarten curriculum guidebooks from China and South Korea, according to the dimensions and indicators of comparative analysis, both are examined together to find their similarities and differences, to grasp and compare their characteristics between similarities and differences. (Crossley \& Watson, 2003). This research design mainly refers to collecting, sorting, and identifying literature on the kindergarten curriculum theme in China and South Korea. The objective and scientific understanding under the composition will be constructed.

\section{Theoretical Framework}

\subsection{View of Curriculum}

There are many opinions about the definition of curriculum, and each description has a different emphasis. Influenced by different educational views, philosophical views, children's views, and learning perspectives.Defining the curriculum in terms of objectives, which has perfected this idea of expected learning outcomes and goals as a curriculum. The curriculum is not concerned with what the students are going to do in the learning situation, but with what they will learn (or be able to do) due to their behavior, not with what has happened. The curriculum is regarded as some educational and teaching objectives that educators are trying to achieve. That is, the curriculum is the end of the teaching, not the means. Under the influence of American scholar Dewey's progressive educational thought, it emphasized that children's experience should be taken as curriculum, children's interests and needs should be respected, and children's personalities should be developed (Feinberg, 2018). This view holds that the curriculum is all the experience that learners acquire under the teacher's guidance. Children learn by doing, and the basic focus of the experiential curriculum is on the child's interests and motivations, with motivation at the center of the teaching organization.

\subsection{View of Kindergarten Curriculum and Guidebook}

The kindergarten curriculum is a system of curriculum objectives, contents, methods, and evaluation. It is an intermediary or bridge for transforming educational thoughts and theories into the practice of preschool education. Kindergarten curriculum and other education stages at all levels of the curriculum of various types of knowledge, although there are similarities, there are differences in many ways. The most obvious difference is in the examination of the educational objects. The kindergarten curriculum's decision with children as the educational objects requires educators to pay more attention to individual children's development level. (Flores, 2016) The kindergarten curriculum is the means to achieve kindergarten education, which is to help children get beneficial learning experience, promote the comprehensive and harmonious development of the body and mind of all kinds of activities.A curriculum guidebook is an important material for students with specific educational objectives, learning contents, and learning activities. It is the material for teachers to teach and the media for students to understand the world. It is the medium for teachers to transfer knowledge for students to learn. To achieve particular teaching objectives, all resources and materials, including teacher guidance manuals, guidebooks for students, audio-visual materials, and functional materials, provide content and methods for teachers' education and teaching and students' learning, which are the media connecting teachers and students.

\section{Comparative Analysis}

This part makes a specific textual comparison and analysis of two sets of kindergarten curriculum guidebooks from China and South Korea. Both of kindergarten curriculum guidebooks are compared from five aspects: guiding ideology, frame structure, teaching goal, teaching content, and implementation strategy.

\subsection{Comparative Analysis of Guiding Ideology}

Ecological education is the guiding ideology of the Kindergarten curriculum in China. Its concrete expression is as follows: first, emphasizing the formation of sustainable development target ecology. The ultimate goal is the constant progress and development of children, teachers, and education. It focuses on how much knowledge and skills children have mastered and focuses on their experience acquisition and emotional experience in acquiring knowledge. Second, it advocates the formation of the content ecology of domain integration. Take children as a whole, and the experience they gain through experience, inquiry, and communication is also a whole.

The kindergarten curriculum in South Korea is based on proper life education, such as cultivating children's essential living habits, obeying the order, learning to care, and knowing how to cooperate. As members of the 
social community, to live a healthy and happy life, individuals should develop essential life habits and form a correct life from early childhood. The emphasis is on respect for man and nature, emphasizing respect for the country's culture. Encourage children to learn to observe, listen, and feel each other, starting from understanding, mutual certification, tolerance, and assistance. Respect nature and respect the relationship between personality and human beings (Na \& Jang, 2001). In this sense, the objectives and contents of its various fields emphasize the coexistence of man and nature, emphasizing the integrity of its own culture. Also, it contains the development of children's creative and creative thinking ability of the guiding ideology connotation. It emphasizes that children's own experience is the top way, and games and activities are the primary way to promote children's comprehensive and balanced development.

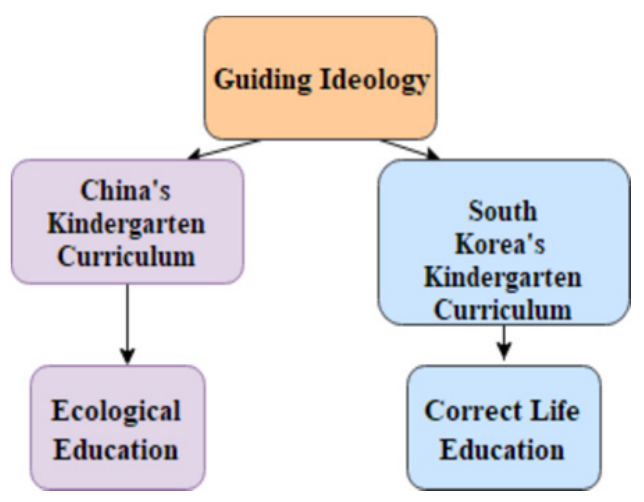

Figure 1. Comparative analysis of guiding ideology

Through the comparison above, both emphasize the balanced development of children, and both emphasize the acquisition of children's own experience and various emotions and emotional experiences during the purchase of experience and highlight the process of children's experience rather than knowledge and skills eventually learned. The difference between both: the core purpose of the guiding ideology is different. The teaching materials of the Kindergarten curriculum in China clearly define its guiding ideology, namely ecological education, and then refine the ecological education concept into target ecology, content ecology, environmental ecology, and teacher-student relationship ecology try to explore the kindergarten curriculum field from a multi-field perspective. The guiding ideology of Kindergarten teaching materials in South Korea is to focus on the cultivation of children's correct essential living habits and proper life education and to be able to respect people and nature, respect the culture of the country, and be creative.

\subsection{Comparative Analysis of Frame Structure}

The Chinese kindergarten curriculum guidebook's frame structure centered on different themes, which are mainly composed of six parts: theme description and goals, environment creation and regional setting, daily activities and games, parent work, list of ideas for theme development, and specific activity design. The first part is the theme description and goals. This paper expounds on the theme's overall design idea, explains the relevance between the theme and the five fields, the reason and significance of teaching children the theme, and the expected target of implementing the theme. The second part is environment creation and locale setting. The environment includes theme walls and display areas. The area design of kindergarten includes art area, reading area, puzzle area, role area, living area, as well as the environment creation and material preparation in each area. The third part is about daily activities and games. Briefly introduce the activity related to the theme and the game's leading content and operation method and the significance of implementing the activity or game. The fourth part is the parents' work. Reflect around the theme, the realization of kindergarten, family, social three aspects of the idea of co-construction. The fifth part is a list of ideas. It consists of five parts: the concept of theme development, the name of the activity, the goal of the activity, the focus area and the design area, and the related materials. The sixth part is a specific activity design. It includes six parts: activity target, activity preparation, activity process, activity extension, activity tips, and appendix materials. Teachers can screen and use specific activities according to the class's actual situation and needs.

The South Korea kindergarten curriculum guidebook's frame structure is carried out with different themes, mainly including two parts: the first part is the theoretical part of theme design; The second part is an operational plan for specific activities related to the topic. The first part includes the Life theme summary, which consists of the 
meaning of the life theme and its content composition (Nah \& Kwak, 2011). The general table of educational activities under the theme consists of sub-theme, theme content, activity name, activity type, and main related fields. The overall educational activities plan under the theme includes the general introduction of educational activities and the overall curriculum (including weekly education plan and one-day education plan). The second part includes: the list of educational activities under the theme consists of free choice of activities, large and small group activities, game arrangement, environmental composition, and the connection with family and community society.

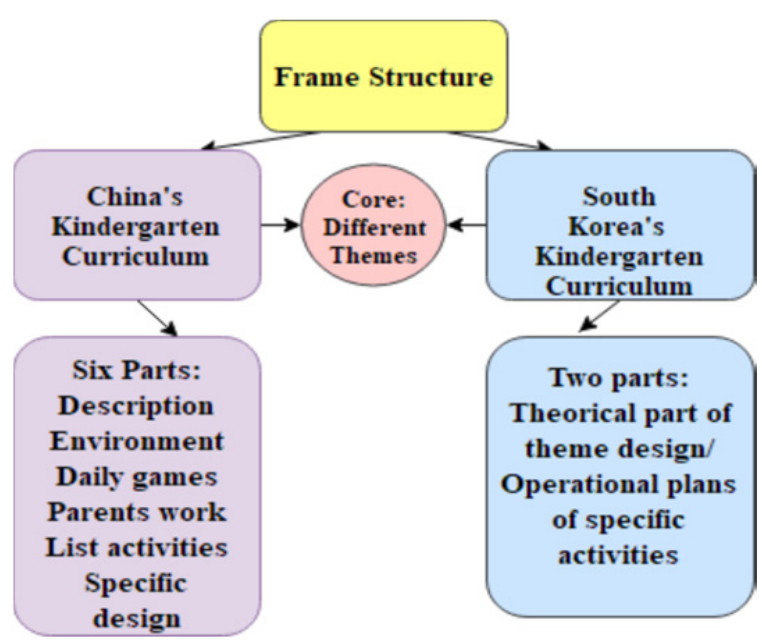

Figure 2. Comparative analysis of frame structure

The two sets of the curriculum frame structure are carried out from different themes to specific activities based on the above. Particular activities are carried out around each unit theme and theme, with a clear hierarchy. Besides, both have a list of themed activities. It includes the subject name, the activity name, the activity target, the emphasis, and the related field, the corresponding material, and so on, facilitating the teacher to grasp the education teaching. Besides, the difference between the two is that the framework of Chinese kindergarten curriculum guidebooks is relatively general. The idea of developing the theme is only a chart, which lacks theoretical support for the connection between the theme and specific activities. However, the curriculum guidebooks for Kindergartens in South Korea divide the teaching contents into each theme in the form of frame charts. Each week and each day, each education and teaching link has a clear weekly goal and a daily goal.

\subsection{Comparative Analysis of General Goal}

The general goal of the Chinese kindergarten curriculum guidebook is that "Kindergarten education should implement the national educational policy, adhere to the principle of integrating conservation and education, and develop physical, intellectual, moral and aesthetic knowledge for preschool children in an all-round way. The content of kindergarten education is enlightening and extensive. According to children's learning activities, kindergarten education and teaching are divided into five teaching fields: health, society, science, language, and art. The specific objectives in each area are as follows: Firstly, the health field. Enhance children's physical quality, develop a healthy body, form a healthy attitude, and maintain good life habits. Secondly, the science field. Develop children's cognitive ability, arouse the desire to forget exploration, cultivate curiosity. Provide diversified resources, organize diversified activities, set different situations for children, and encourage children to explore and find. Third, the social field. Cultivate and strengthen children's self-esteem, self-confidence, develop caring, friendly attitude and behavior, and promote children to develop a healthy personality. Forth, Language field. Promote children to actively participate in language communication activities and develop language communication skills. Fifth, the art field. Cultivate children's initial experience of beauty, the performance of the beauty of interest and ability, rich children's emotions.

The general goal of Korea kindergarten curriculum guidebook is to promote the healthy development of children's body and mind, help them to acquire essential living habits, learn to cooperate with others, be able to express their thoughts and feelings creatively, use language appropriately and think independently about problems in life. Firstly, it involves the following five aspects: Develop basic exercise ability and healthy and safe living habits. Develop children's basic sports ability, form the right attitude and essential habits about health, and develop the ability to 
deal with accidents safely. Secondly, communication and understanding ability and correct language usage habits are required to create daily life habits. Cultivate children to develop proper language use habits and encourage them to express their thoughts, feelings, experiences, etc. Listen carefully to the voice of others, develop children's ability to understand and communicate. Third, build self-esteem and an attitude toward living with others. Encourage children to express positive thoughts about themselves, correct the mindset of people who live with them, and cultivate their correct self-knowledge concept and proper sense of social integrity. Forth, care about beautiful things and enjoy the artistic experience, and develop creative performance ability. Fifth, Children's curiosity explores the surrounding world and develops their capacity and attitude to think in mathematics and science daily.

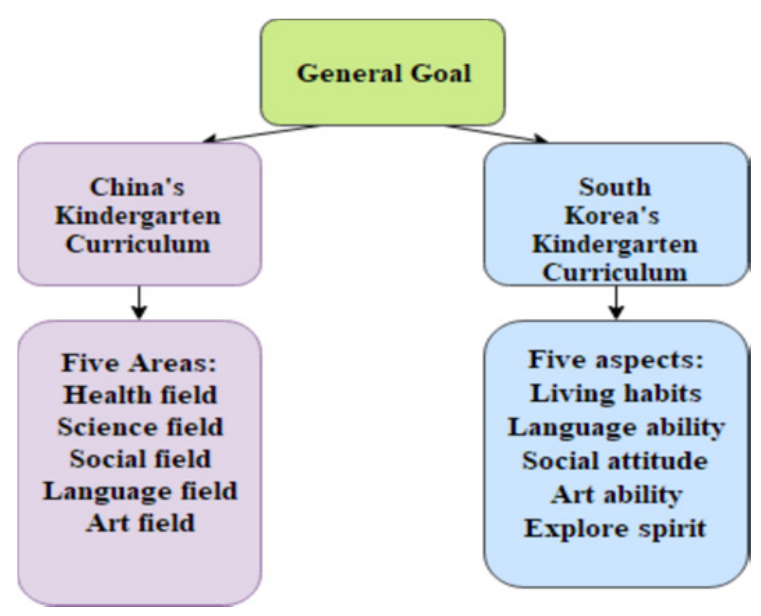

Figure 3. Comparative analysis of general goal

Through textual analysis and comparison of the two general goals, the two's similarities are as follows: First, mainly to the early childhood development of the overall requirements and development direction. Second, the general goal is divided into five levels, namely, "five areas." The five indicators focus on the completion of the overall goal of teaching, and at the same time, they contain specific goals and requirements. Difference between the two: The target content in the same domain is different. Among the goal in health, China's general-goal focuses on children's physical fitness. In the field of health, South Korea emphasizes the cultivation of children's basic sports ability. Also, in terms of a social goal, the Chinese kindergarten curriculum guidebook emphasizes the cultivation of children's self-esteem and emphasizes the cultivation of a good personality. In science, South Korea kindergarten guidebooks emphasize the cultivation of scientific research attitude and solve simple problems in life. It can be seen that the Chinese kindergarten curriculum guidebook focus on the cultivation of children's skills. In contrast, the South Korea kindergarten curriculum guidebook can better reflect Korean kindergarten education on children's emotions and attitudes.

\subsection{Comparative Analysis of Educational Contents}

The Chinese kindergarten curriculum guidebook (in the form of curriculum themes) includes 16 theme curriculums that include 453 specific theme activities. On the other hand, the educational contents (in the way of curriculum themes) of the South Korea kindergarten curriculum guidebook include 11 theme curriculums, including 657 specific theme activities.A statistical and quantitative analysis of the two sets, the following results are obtained: Chinese kindergarten curriculum guidebook focus on 50 theme activities in the health field, accounting for $11 \%$ of the total activities, and 82 theme activities focusing on the language field, accounting for $18 \%$ of the total, 72 theme activities focused on the science field, accounting for $16 \%$ of the total, 140 theme activities focused on the social area, accounting for $31 \%$ of the total, and 109 theme activities focused on the art field which accounted for $24 \%$ of the total. On the other hand, the South Korea kindergarten curriculum guidebook focus on 59 theme activities in the health field. Accounting for $9 \%$ of the total, 85 theme activities in the language field, accounting for $13 \%$ of the total, and 171 theme activities in the science field, accounting for $26 \%$ of the total, 250 theme activities focusing on the social area, accounting for $38 \%$ of the total. Ninety-two theme activities are focusing on the art field, accounting for $14 \%$ of the total. The specific data collection and analysis comparison are shown in the figure below: 


\begin{tabular}{|l|r|r|}
\hline & $\begin{array}{l}\text { China kindergarten's } \\
\text { educational contents }\end{array}$ & $\begin{array}{l}\text { South korea } \\
\text { kindergarten's } \\
\text { educational contents }\end{array}$ \\
\hline Health field & 50 & 59 \\
\hline Language field & 82 & 85 \\
\hline Science field & 72 & 171 \\
\hline Social field & 140 & 250 \\
\hline Art field & 109 & 92 \\
\hline
\end{tabular}

Figure 4. Comparative analysis of educational contents

According to the above figure analysis, the two theme activities that focus on the social field have the largest proportion, and the health field has the smallest balance. The big difference between both is in the field of science and society. Korea kindergarten curriculum pays more attention to the development of children in the field of science and culture. Chinese kindergarten curriculum pays more attention to the development of children in the field of art and society.

\subsection{Comparative Analysis of Implementation Characteristic}

The implementation characteristics of Chinese kindergarten curriculum guidebook are as follows: First, the target of the curriculum implementation plan is children of the corresponding age, the leader of the curriculum implementation plan is the kindergarten teachers, and the Chinese kindergarten teachers need to obtain a variety of certificates before carrying out kindergarten teaching practice. (such as teacher qualification certificate, piano level certificate, art painting certificate or dance certificate, etc.). Kindergarten teachers also carry out the art curriculum of Chinese kindergarten. Second, before the specific curriculum teaching activities are carried out, the teachers pre-set specific curriculum theme activities based on the kindergarten teaching plan, including specific curriculum introduction, curriculum goals, teaching aid preparation, curriculum evaluation, etc. Third, collaborative teaching is the main teaching method, focusing on forming children's rules awareness during the curriculum process. Fourth, as for the results of curriculum implementation, pay attention to the expression of children's emotions and emotions, but pay more attention to children's acquisition of knowledge or skills after the curriculum. Fifth, actively learn and absorb Western preschool education concepts and combine the traditional characteristics to form a kindergarten's characteristics curriculum with traditional Chinese culture.

The characteristics of the South Korea kindergarten curriculum guidebook's implementation are as follows: First, to provide children with diversified activities centered on children. Child-centered refers to the development of children's physical and mental development as the goal. Second, the curriculum implementation method is flexible, mainly based on generative courses, and does not emphasize pre-set curriculum plans in advance. Kindergarten teachers in South Korea need to obtain a teacher qualification certificate before starting kindergarten curriculum activities, who pay more attention to teachers' deeply understanding and grasp of curriculum activities' spirit. Most of the art curriculums will invite professional art teachers to teach in kindergartens.Third, teaching focuses on group activities and outdoor games, focusing on children's free choice, and paying more attention to children's participation and expression of emotions and emotions in the course of implementation. Fourth, the curriculum implementation plan has specific instructions corresponding to the detailed teacher's instruction manual, which is more convenient for kindergarten teachers to improve curriculum implementation efficiency. By comparing the two sets' implementation characteristics, we conclude the similarities between the two: Emphasizing children as the education's center. There are corresponding national standards for the qualifications of kindergarten teachers. Kindergarten teachers are required to be familiar with and grasp the kindergarten curriculum materials. Also, there are differences of both: South Korea kindergarten curriculum implementation emphasizes children's emotions' expression and experience. In contrast, Chinese kindergarten curriculum implementation focuses more on acquiring knowledge and skills. South Korea kindergarten curriculum implementation methods are mainly generative, and Chinese kindergarten will pre-set the curriculum implementation plans and methods.

\section{Suggestions}

This study compares and analyzes the similarities and differences from the five aspects of the guiding ideology, framework structure, general goal, educational contents, and implementation characteristic. The two sets of 
kindergarten curriculum guidebooks between China and South Korea provide kindergarten educators as a reference. The following suggestions: First, attach importance to the overall grasp and in-depth understanding of the kindergarten curriculum materials, and reflect on the reasons for the design of the curriculum framework and how it is carried out. Second, starting from the local reality, thinking about the process and possible problems from the overall goal of the kindergarten curriculum to the practice of the kindergarten curriculum, drawing on the comparison results of the two countries in this article, and reflecting on what individuals can learn from or innovate in specific teaching practices. Third, from an international perspective, reflect on the focus of the domestic kindergarten curriculum's educational content and the current educational problems in the country and try to find possible causes or solutions from international comparisons.

\section{References}

Crossley, M., \& Watson, K. (2003). Comparative and International Research In Education: Globalisation, Context and Difference (1st ed.). https://doi.org/10.4324/9780203452745

Feinberg, W. (2018). Dewey and Education (1st ed.). https://doi.org/10.4324/9781351049795

Flores, R. L. (2016). Using Early Learning Standards to Provide High-Quality Education for All Children: The Early Learning Guidelines Toolkit. Theory into Practice, 55(2), 145-152. https://doi.org/10.1080/00405841.2016.1157422

Lee, K. S. (1996). Culture and the Korean kindergarten curriculum. Early Child Development and Care, 123(1), 167-182. https://doi.org/10.1080/0300443961230112

Na, J., \& Jang, M. (2001). Development of Early Childhood Education Indicators. Korea Educational Development Institute.

Nah, K. O., \& Kwak, J. I. (2011). Child assessment in early childhood education and care settings in South Korea. Asian Social Science, 7(6), 66-78. https://doi.org/10.5539/ass.v7n6p66

Neuman, S. B., \& Roskos, K. (2005). The state of state pre-kindergarten standards. Early Childhood Research Quarterly, 20(2), 125-145. https://doi.org/10.1016/j.ecresq.2005.04.010

Qiu, Y. (2019). Research Review on Kindergarten Curriculum Gamification in China. OALib, 6(12), 1-9. https://doi.org/10.4236/oalib.1105934

Xia, B., \& Jin, H. (2012). Kindergarten Experience, Inquiry, and Communication Curriculum in China. Zhejiang Education Press.

Yuejuan, P., \& Yan, L. (2008). A comparison of curricular practices in Chinese kindergartens: The influence of curriculum reform. International Journal of Early Childhood, 40(2), 33-48. https://doi.org/10.1007/BF03165838

Zhu, J. (2009). Early Childhood Education and Relative Policies in China. International Journal of Child Care and Education Policy, 3(1), 51-60. https://doi.org/10.1007/2288-6729-3-1-51

\section{Copyrights}

Copyright for this article is retained by the author(s), with first publication rights granted to the journal.

This is an open-access article distributed under the terms and conditions of the Creative Commons Attribution license (http://creativecommons.org/licenses/by/4.0/). 